\title{
Sakarya Üniversitesi' nde Laparoskopik Ürolojik Cerrahi: Başlangıç Deneyimlerimiz
}

\author{
Laparoscopic Urological Surgery In Sakarya University: \\ Our Initial Experience \\ Hacı Ibrahim Çimen, Yavuz Tarık Atik, Burak Uysal, Fikret Halis, \\ Ahmet Gökçe, Hasan Salih Sağlam
}

Sakarya Üniversitesi, Tıp Fakültesi, Üroloji AD, Sakarya

Yazışma Adresi / Correspondence:

Hacı Ibrahim Çimen

Sakarya Üniversitesi, Tıp Fakültesi, Üroloji AD, Sakarya

T: +90538 $3928434 \quad$ E-mail: dr.ibrahimcimen@gmail.com

Geliş Tarihi / Received : 14.05.2018 Kabul Tarihi / Accepted : 30.05.2018

Öz

Amaç Laparoskopik ürolojik cerrahideki başlangı̣ç sonuçlarımııı sunmak. ( Sakarya Tip Dergisi, 2018, 8(2):416-422 )

Gereç ve Ocak 2015 ile Ocak 2018 tarihleri arasında kliniğimizde laparoskopik ürolojik cerrahi uygulanan hastaların sonuçları retrospektif olarak Yöntem değerlendirildi.

Bulgular Kliniğimizde laparoskopik cerrahi yapılan 88 hastanın 50 ' si $(\% 56,8)$ erkek, 38' i $(\% 43,2)$ kadındı. Hastaların ortalama yasıı $56 \pm 14(17$ 86) yıl idi. Otuz altı hastaya radikal nefrektomi, 26 hastaya basit nefrektomi, 3 hastaya parsiyel nefrektomi, 9 hastaya nefroüreterektomi, 2 hastaya dismembered piyeloplasti, 4 hastaya adrenalektomi, 7 hastaya üreterolitotomi, 1 hastaya ise orșiektomi uygulandı. Ortalama operasyon süresi sırasıyla $130 \pm 20,119 \pm 21,140 \pm 5,150 \pm 21,117 \pm 3,71 \pm 8,80 \pm 11$ ve $45 \mathrm{dk}$, ortalama hastanede kalıs süreleri sırasıyla $4,2 \pm 1,3,3,1 \pm 1,4,4,3 \pm 1,5,4,7 \pm 1,3,4 \pm 1,4,3 \pm 0,8,2,8 \pm 1$ ve 1 gündü. Radikal nefrektomi yapılan hastaların 4 ' ünde, basit nefrektomi yapılan hastaların 6' sında ve nefroüreterektomi yapılan hastaların 3' ünde olmak üzere toplam $13(\% 14,7)$ hastada açık cerrahiye geçildi. Postoperatif komplikasyon $11(\% 12,5)$ hastada görüldü.

Sonuç Laparoskopik cerrahi; öğrenme eğrisi uzun olan, cerrahın yeteneğine ve tecrübesine bağlı olarak cok iyi fonksiyonel sonuçlar veren minimal invaziv cerrahi yöntemlerden birisi olarak başlangıç döneminde uygun hasta seçimi ve doğru planlama ile başarilı bir şekilde uygulanabilmektedir.

Anahtar Laparoskopik cerrahi; üroloji; deneyim

Kelimeler

Abstract

Purpose To evaluate our initial experience in laparoscopic urological surgery. ( Sakarya Med J, 2018, 8(2):416-422 ).

Materials and The results of patients who underwent laparoscopic surgery between January 2015 and January 2018 were retrospectively evaluated.

Methods

Results Of the 88 patients, $50(56.8 \%)$ were male and $38(43.2 \%)$ were female. The mean age of the patients was $56 \pm 14(17-86)$ years. Surgical procedures were radical nephrectomy in 36 patients, simple nephrectomy in 26 patients, partial nephrectomy in 3 patients, nephroureterectomy in 9 patients, dismembered pyeloplasty in 2 patients, adrenalectomy in 4 patients, ureterolithotomy in 7 patients, and orchiectomy in 1 patient. The mean operation time was $130 \pm 20,119 \pm 21,140 \pm 5,150 \pm 21,117 \pm 3,71 \pm 8,80 \pm 11$ and 45 minutes, respectively. The mean length of hospital stay was $4.2 \pm 1.3,3.1 \pm 1.4,4.3 \pm 1.5,4.7 \pm 1.3,4 \pm 1.4,3 \pm 0.8,2.8 \pm 1$ and 1 days, respectively. Conversion to open surgery was required in $13(14.7 \%)$ patients including 4 patients underwent radical nephrectomy, 6 patients underwent simple nephrectomy and 3 patients underwent nephroureterectomy. Postoperative complications were observed in $11(12.5 \%)$ patients.

Conclusion Laparoscopic surgery, which is a minimal invasive surgery, has a long learning curve but it can be performed successfully due to the experience and ability of a surgeon with a suitable patient choice and correct planning at the beginning.

KeyWords Laparoscopic surgery; urology; experience 


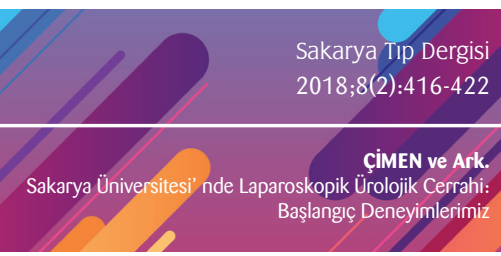

Sakarya TIp Dergis

CiMEN ve Ark Başlangıç Deneyimlerimiz

\section{Giriş}

Laparoskopik cerrahinin geçmişi 1900'lü yıllara dayanırken ürolojik cerrahi alanında son 30 yıldır kullanılmaktadır. Minimal invaziv cerrahi tercihinin artması ve teknolojinin de ilerlemesiyle son dönemde laparoskopik cerrahi daha fazla tercih edilir hale gelmiştir. Ürolojide laparoskopi ilk kez 1990 yllında lokalize prostat kanserli hastalarda pelvik lenfadenektomi yapmak için kullanılmış sonrasında Clayman ve ark. larının yaptıkları ilk laparoskopik radikal nefrektomiyi takiben 1991 ylında ilk basit nefrektomi, mesane boynu süspansiyonu ve nefroüreterektomi; 1992 ylında ise ilk varikoselektomi, adreneleketomi ve piyeloplasti ameliyatları yapılmıştır. ${ }^{1}$

Açık cerrahide yüksek morbidite ve postoperatif ağrının fazla olması neredeyse benign ve malign tüm ürolojik vakalarda tedavi modalitesi olarak laparoskopinin sık kullanilır hale gelmesine sebep olmuştur. Açık cerrahiye göre minimal invaziv cerrahinin daha iyi hasta konforu, daha kabul edilebilir kozmetik sonuçlar ve daha kısa günlük hayata dönüş süresi gibi avantajları bulunmaktadır. ${ }^{2}$ Bunun yanında öğrenme eğrisinin uzun olması, yüksek maliyet ve başlangıç döneminde komplikasyon oranlarının daha fazla görülmesi ve operasyon başarısın cerrahın deneyimine bağlı olması bu prosedürün dezavantajları olarak görünmektedir.

Bu çalışmada Sakarya Üniversitesi Tıp Fakültesi Üroloji kliniğinde laparoskopik ürolojik cerrahi uygulanan hastaların sonuçlarını değerlendirmeyi amaçladık.

\section{Gereç ve yöntem}

Etik kurul onayı alındıktan sonra Ocak 2015 ile Ocak 2018 yılları arasında Sakarya Eğitim ve Araştırma Hastanesi Üroloji kliniğinde laparoskopik cerrahi uygulanan 88 hastanın verileri retrospektif olarak değerlendirildi. Tüm vakalar aynı cerrahi ekip tarafından ameliyat edildi ve tümünde transperitoneal yaklaşım tercih edildi. Hastaların demografik özellikleri, yapılan ameliyatın türü ve süresi, preoperatif ve postoperatif hemoglobin düzeyleri, hastanede kalış süreleri kaydedildi. Postoperatif komplikasyonların değerlendirmesi Clavien-Dindo sınıflama sistemine göre yapıldı. Tanımlayıcı istatistikler IBM SPSS 22 programı kullanılarak yapıldı. Veriler ortalama \pm standart sapma ve yüzde olarak belirtildi.

\section{Cerrahi Teknik}

Laparoskopik cerrahilerin tümünde transperitoneal yaklaşım tercih edildi. Genel anestezi altında hastalara $70^{\circ}$ lateral dekübit pozisyonu verildi. illk giriş umblikus ile spina iliaka anterior superior arasındaki hattın 1/3 dış noktasından Veress iğnesi ile yapıldı. Ardından $15 \mathrm{mmHg}$ ile pnömoperitoneum oluşturuldu. Ardından bu noktadan $10 \mathrm{~mm}$ trokar ile batın içine girildi. ikinci 10 mm'lik trokar direk görüş altında rektus kasının lateral sınıгında umblikusun medialine konuldu. Üçüncü 5 mm'lik trokar ön aksiler hatta 11. kot ucunun 1-2 cm altından konuldu (Şekil 1). Solda genel-likle 3 port kullanılırken, sağda gerektiğinde karaciğer ekartasyonu için 5 mm'lik 4. trokar girildi. Ardından batın içi basınç $12 \mathrm{mmHg}$ olarak ayarlandı. Radikal ve basit nefrektomide önce Toldt hattı insize edilerek kolon mobilize edildi ve mezokolon Gerota fasiyasından ayrıldı. Üreter psoas kasının üzerinde vizualize edilerek diseke edildi ve asıldı. Üreter kılavuzluğunda böbrek hilumuna ulaşıldı. Böbrek arter ve veni ayrı ayrı diseke edildi. ilk önce böbrek arteri kliplendi ve kesildi. Böbrek arterinin kontrolünün ardından böbrek veni diseke edilerek kliplendi ve kesildi. Endikasyonu olmayan vakalarda adrenal bez böbrek üst polünden ayrıldı ve korundu. Üreter ve gonadal damarlar ayrı ayґı kliplendi ve kesildi. Spesmenler endobag içine alındı ve vücut dışına çıkartıldı. Nefroüreterekto- 
mi prosedüründe öncelikle litotomi pozisyonunda rezektoskop ile girilerek üreterektomi yapılacak olan taraf orifisin çevresi transüretral prostat insizyon bıçağı yardımı ile insize edildi. Orifis ve üreterin intramural kısmı yağı doku görünene kadar mesaneden ayrıldı ardından standart radikal nefrektomi prosedürü uygulandı. Bu hastalarda sonda postoperatif 7. günde sistogramda ekstravazasyon olmadığı görülerek çıkarıldı. Üreterolitotomi operasyonunda taşın olduğu kısma longitidünal kesi yapılarak taş grasper yardımıyla alındı. Anterograd çift J stent yerleştirilmesinin ardından üreterdeki insizyon 4/0 Vicryl ile kapatıldı. Adrenalektomide ise portlar uygun şekilde yerleştirildikten ve batına girildikten sonra böbrek üst polü serbestlendi. Ardından sürrenal ven kliplendi, daha sonra diğer sürrenal damarlar kesilerek sürrenal bez çıkartıldı. Dismembered piyeloplasti operasyonları önce $\neg$ Sinde retrograd üreter katateri yerleştirildi. Üreter renal pelvisten ayrılmadan spatüle edildi. Fazla olan pelvis dokusu laparoskopik makas yardımı ile eksize edildi. Anastamozda 4-0 emilebilir monoflaman dikiş materyali kullanıldı.

\section{Bulgular}

Kliniğimizde laparoskopik cerrahi yapılan 88 hastanın 50' si $(\% 56,8)$ erkek, 38' i $(\% 43,2)$ kadındı. Hastaların ortalama yaşı 56ะ14 (17-86) yı idi. Otuz altı hastaya radikal nefrektomi, 26 hastaya basit nefrektomi, 3 hastaya parsiyel nefrektomi, 9 hastaya nefroüreterektomi, 2 hastaya dismembered piyeloplasti, 4 hastaya adrenalektomi, 7 hastaya üreterolitotomi, 1 hastaya ise orşiektomi (32 yaşında intraabdominal testis nedeniyle) uygulandı (Tablo 1).

\begin{tabular}{|l|c|c|c|}
\hline \multicolumn{5}{|l|}{ Tablo 1. Laporoskopik cerrahi sayısı ve operasyon verileri } \\
\hline Yapılan operasyon & Hasta sayısı,n, \% & $\begin{array}{c}\text { Operasyon süresi, dk, } \\
\text { ortalama } \pm \text { standart sapma }\end{array}$ & $\begin{array}{c}\text { Yatış süresi, gün, } \\
\text { ortalama } \pm \text { standart sapma }\end{array}$ \\
\hline Radikal nefrektomi & $36(\% 41)$ & $130 \pm 20$ & $4,2 \pm 1,3$ \\
\hline Basit nefrektomi & $26(\% 29,5)$ & $119 \pm 21$ & $3,1 \pm 1,4$ \\
\hline Parsiyel nefrektomi & $3(\% 3,4)$ & $140 \pm 5$ & $4,3 \pm 1,5$ \\
\hline Nefroüreterektomi & $9(\% 10,2)$ & $150 \pm 21$ & $4,7 \pm 1,3$ \\
\hline Pyeloplasti & $2(\% 2,3)$ & $117 \pm 3$ & $4 \pm 1,4$ \\
\hline Adrenalektomi & $4(\% 4,5)$ & $71 \pm 8$ & $3 \pm 0,8$ \\
\hline Üreterolitotomi & $7(\% 8)$ & $80 \pm 11$ & $2,8 \pm 1$ \\
\hline Orşiektomi & 1 & 45 & 1 \\
\hline
\end{tabular}

Ortalama operasyon süresi sırasıyla $130 \pm 20,119 \pm 21,140 \pm 5,150 \pm 21,117 \pm 3,71 \pm 8,80 \pm 11$ ve $45 \mathrm{dk}$; ortalama hastanede kalış süreleri ise sırasıyla 4,2 $\pm 1,3,3,1 \pm 1,4,4,3 \pm 1,5,4,7 \pm 1,3,4 \pm 1,4$, $3 \pm 0,8,2,8 \pm 1$ ve 1 gündü. Laparoskopik radikal nefrektomi, parsiyel nefektomi, basit nefrektomi, nefroüreterektomi ve adrenelektomi yapılan hastaların preoperatif ortalama hemoglobin düzeyleri sırasıyla $12,8 \pm 1,94 ; 12,2 \pm 1,8 ; 13,5 \pm 1,53 ; 12 \pm 2,0$ ve $13 \pm 0,79 \mathrm{gr} / \mathrm{dl}$, postoperatif ortalama hemoglobin düzeyleri ise sırasıyla 11,2 $\pm 1,54 ; 10,6 \pm 1,99 ; 12,2 \pm 1,77 ; 10,7 \pm 1,32$ ve 12,2 2 2,26 gr/dl olarak saptandı. Toplam $13(\% 14,7)$ hastada açık cerrahiye geçildi. Bu hastaların 4 tanesine radikal nefrektomi, 6 tanesine basit nefrektomi ve 3 tanesine nefroüreterektomi yapıldı. Açık cerrahiye geçilme sebebi 2 hastada peroperatif kanama sebebiyle görüşün bozulması, 1 hastada postop erken dönemdeki kanama, 7 hastada peroperatif yapışıklık olması nedeniyle diseksiyonun sürdürülememesi, 2 hastada peroperatif CO2 satürasyonun yükselmesi ve 1 hastada ise peropeatif duedonum yaralanması olarak tespit edildi (Tablo 2). Toplam 11 (\%12,5) hastada postoperatif komplikasyon görüldü. Clavien-Dindo komplikasyon sınıflamasına göre 8 hastada 2. derece, 1 hastada 3a derece, 1 hastada $3 b$ derece ve 1 hastada 5 . derece komplikasyon gözlendi (Tablo 3). íkinci derece
Sakarya Tıp Dergisi

2018;8(2):416-422 ÇiMEN ve Ark.
Sakarya Üniversitesi' nde Laparoskopik Ürolojik Cerrahi: Başlangiç Deneyimlerimiz 
mi vakalarının sonuçlarını yansıtmaktadır. ilerleyen dönemde laparoskopik olarak daha kompleks cerrahilerin yapılmasına bağı olarak komplikasyon oranları da artmış ve \%12-13 seviyelerine kadar çıkmıştır. ${ }^{8-10}$ Çalışmamızda komplikasyon oranımız $\% 12,5$ olarak bulundu ve literatürle uyumlu olarak değerlendirildi. Laparoskopik ürolojik cerrahide vasküler komplikasyon oranları \%0,03 ile \%2,7 olarak bildirilmiştir. ${ }^{11}$ Çalışmamızda \%3,4 olarak saptanan ve literatüre göre yüksek bulunan bu oranın toplam vaka sayısının az ve kompleks vaka sayısının fazla olmasına bağlı olarak yüksek olduğunu düşünmekteyiz.

Açık cerrahiye geçme oranları ile ilgili prosedürün zorluğuna ve kişisel yeteneğe bağlı olarak literatürde farklı sonuçlar görülmektedir. Rasweiler ve ark. ilk 100 vakalık retroperitoneal laparoskopi serilerinde açık cerrahiye geçme oranlarını \%17 olarak belirtirken, aynı çalışmanın devamı olarak nitelendirilen 200 vakalık laparoskopik cerrahinin sonuçlarını yayınlamışlar ve açık cerrahiye geçme oranlarının son 50 vakada $\% 2$ seviyesine gerilediğini, cerrahi tecrübe arttıkça açık cerrahiye geçişin azaldığını bildirmişlerdir. ${ }^{12}$ Permpongkosol ve ark' nın 2007 yılında yayınladıkları 2775 vakalık laparoskopik cerrahi serilerinde $74(\% 2,67)$ hastada açık cerrahiye geçildiğini bildirmişler ve öğrenme eğrisindeki cerrahların uygun hasta seçimi ve ameliyat öncesi iyi planlama ile bu oranı düşürebileceğini göstermişlerdir. ${ }^{13}$ Çalışmamızda açık cerrahiye geçme oranı $\% 14,7$ olarak saptanmıştır. Açık cerrahiye geçilen hastalar incelendiğinde 7 hastada ileri derecede yapışıklık olması ve diseksiyona izin vermemesi, 3 hastada kanama nedeniyle görüşün bozulması, 2 hastada hiperkapni ve 1 hastada duedonum yaralanması nedeniyle açık cerrahiye geçildiği tespit edildi.

Guillonneau ve ark 2001 yilında Avrupa skorlama sistemi geliştirerek laparoskopik olarak yapılması zor vakaları belirlemişlerdir. ${ }^{14}$ Çalışmamızda her ne kadar vasküler komplikasyon ve açık cerrahiye geçme oranlarımız mevcut literatüre göre yüksek görünse de serimizdeki 88 vakanın 48 (\%54,4)' inin Avrupa skorlama sistemine göre yapılması zor prosedürlerden oluştuğu görüldü. Komplikasyon oranımızın yüksekliğinin öğrenme eğrisinde yapılması zor prosedürlerin fazlalığına bağlı olduğunu düşünmekteyiz.

Laparoskopik komplikasyonları açık cerrahiye bağlı komplikasyonlardan ayıran başka bir husus ise pnömoperitoneum esnasında kullanılan $\mathrm{CO} 2$ insuflasyonuna bağlı gelişen hiperkarbidir ve sık görülen komplikasyonlardan birisidir. Çalışmamızda 2 hastada hiperkarbi nedeniyle açık cerrahiye geçilmiştir.

Vallancien ve ark. tek merkezli 1311 hastalık çalışmalarında laparoskopide yeterliliğin sağlanması için en az 50 zor vakanın yapılması gerektiğini ve böylece kan kaybı ve operasyon sürelerinin azalacağını belirtmişlerdir. ${ }^{15}$ Tuncel ve arkadaşları 35 vakalık laparoskopik adrenelektomi serilerinde

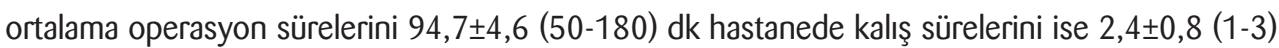
gün olarak bildirmişlerdir. ${ }^{16}$ Zacharias ve ark. nın 2006 ylında yayınladıkları 54 vakalık laparoskopik adreneleoktomi çalışmalarında ortalama operasyon süresini 125 (70-220) dk olarak belirtmişlerdir.17 Bizim çalışmamızda da ortalama operasyon süresi $71 \pm 8 \mathrm{dk}$ olarak saptandı ve literatürle uyumlu olduğu görüldü.

Kural ve ark. laparoskopik nefrektomideki ilk deneyimlerini paylaştıkları 42 vakalık çalışmalarında ortalama operasyon süresini laparoskopik basit nefrektomi için $150 \mathrm{dk}$, radikal nefrektomi için $210 \mathrm{dk}$ olarak belirtmişlerdir. ${ }^{18}$ Rassweiler ve ark. nın 14 merkezli 482 laparoskopik nefrektominin cerrahi sonuçlarını değerlendirdikleri çalışmada transperitoneal cerrahilerin ortalama operasyon
Sakarya Tıp Dergisi

$2018 ; 8(2): 416-422$ ÇiMEN ve Ark.
Sakarya Üniversitesi' nde Laparoskopik Ürolojik Cerrahi: Başlangiç Deneyimlerimiz 
Sakarya TIP Dergisi

2018;8(2):416-422

süresini $178 \mathrm{dk}$, ortalama hastanede kalış sürelerini 5,4 (3-9) gün olarak bildirmişlerdir. ${ }^{19}$ Hatipoğlu ve ark. laparoskopik ilk 100 vakalarını değerlendirdikleri çalışmasında operasyon sürelerini basit nefrektomi için 95 (70-135) dk, radikal nefrektomide ise 148 (125-190) dk, ortalama hastanede kalış sürelerini ise sırasıyla 1,5 (1-7) ve 1,8(1-8) gün olarak saptamışlardır. ${ }^{20}$ Bizim çalışmamızdaki operasyon süreleri ve ortalama hastanede kalış süreleri literatürle karşılaştırılabilir düzeyde bulundu.

\section{Sonuç}

Minimal invaziv cerrahi her geçen gün daha da ön plana çımakta ve birçok açı prosedürün yerini endoskopik yaklaşımlar almaktadır. Laparoskopik cerrahi; öğrenme eğrisi uzun olan, cerrahın yeteneğine ve tecrübesine bağı olarak çok iyi fonksiyonel sonuçlar veren minimal invaziv cerrahi yöntemlerden birisi olarak başlangıç döneminde uygun hasta seçimi ve doğru planlama ile başarılı bir şekilde uygulanabilmektedir. 
1. Gill IS, Clayman RV, McDougall EM. Advances in urological laparoscopy. J Urol 1995; 154: 1275-1294.

2. Cimen HI, Atik YT, Adsan O. Laparoscopic simple nephrectomy patient with situs inversus totalis and left renal hypoplasia: A case report. Can Urol Assoc J 2015; 9: 521- 523.

3. Abdelshehid CS, Eichel L, Lee D, Uribe C, Boker J, Basillote J et al. Current trends in urologic laparoscopic surgery. J Endourol 2005; 19: 15-20.

4. Gozen AS, Akin Y. Are structured curriculums for laparoscopic training useful? A review of current literature. Curr Opin Urol 2015; 25(2): 163-167.

5. Clavien PA, Barkun J, de Oliveira ML, Vauthey JN, Dindo D, Schulick RD et al. The Clavien-Dindo classification of surgical complications: five year experience. Ann Surg 2009; 250: 187-196.

6. Rabbani F, Yunis LH, Pinochet R, Nogueira L, Vora KC, Eastham JA et al. Comprehensive standardized report of complications of retropubic and laparoscopic radical prostatectomy. Eur Urol 2010; 57: 371-386.

7. de la Rosette J), Opondo D, Daels FP, Giusti G, Serrano A, Kandasami SV et al. Categorisation of complications and validation of the Clavien score for percutaneous nephrolithotomy. Eur Urol 2012; 62: 246-255.

8. Fahlenkamp D, Rassweiler J, Fornara P, Frede T, Loening SA. Complications of laparoscopic procedures in urology: experience with 2,407 procedures at 4 German centers. J Urol 1999; 162: 765-771.

9. Parsons JK, Varkarakis I, Rha KH, Jarrett TW, Pinto PA, Kavoussi LR. Complications of abdominal urologic laparoscopy: longitudinal five-year analysis. Urology 2004; 63: 27-32.

10. Gomella LG, Abdel-Meguid TA, Lotfi MA, Hirsch IH, Albala D, Manyak M et al. Laparoscopic urologic surgery outcome assessment. J Laparoendosc Adv Surg Tech A 1997; 7: 77-86.

11. Lasser MS, Ghavamian R. Surgical complications of laparoscopic urological surgery. Arab J Urol. 2012; 10(1): 81-88.
12. Rassweiler JJ, Seemann O, Frede T, Henkel TO, Alken P. Retroperitone oscopy: experience with 200 cases. J Urol 1998; 160(4): 1265-1269.

13. Permpongkosol, S, Link, RE, Su, LM, Romero FR, Bagga HS, Pavlovic CP et al. Complications of 2,775 urological laparoscopic procedures: 1993 to 2005. J Urol 2007; $177: 580-585$

14. Guillonneau B, Abbou CC, Doublet JD, Gaston R, Janetschek G, Mandressi A et al. Proposal for a European Scoring System for laparoscopic operations in urology. Eur Urol, 2001; 40: 2-6.

15. Vallancien G, Cathelineau X, Baumert H, Doublet JD, Guillonneau B. Complications of transperitoneal laparoscopic surgery in urology: review of 1,311 procedures at a single center. J Urol 2002; 168: 23-26.

16. Tuncel A, Balcı M, Köseoğlu E, Aslan Y, Güzel Ö, Keten T et al. Transperitoneal laparoscopic adrenalectomy: five years' experience with 35 patients. Turk J Urol 2013; 39: 214-219.

17. Zacharias M, Haese A, Jurczok A, Stolzenburg JU, Fornara P. Transperitoneal laparoscopic adrenalectomy:outline of the preoperative manage ment, surgical approach and outcome. Eur Urol 2006; 49: 448-459.

18. Kural AR, Demirkesen O, Akpınar H, Tüfek I, Yalçın V, Özkan B. Laparoskopik nefrektomide bașlangıç deneyimlerimiz. Türk Üroloji Derg 2004; 30: 414- 421.

19. Rassweiler J, Fornara P, Weber M, Janetschek G, Fahlenkamp D, Henkel T et al. Laparoscopic nephrectomy: the experience of the laparoscopic working group of the German Urological Association. J Urol 1998; 160 18-21.

20. Hatipoğlu NK, Penbegül N, Söylemez H, Atar M, Bozkurt Y, Sancaktutar AA et al. Ürolojik Laparoskopik Cerrahi: Dicle üniversitesindeki ilk 100 deneyimimiz. J Clin Exp Invest 2012; 3(1): 44-48.
Sakarya Tıp Dergisi

$2018 ; 8(2): 416-422$

\section{ÇIMEN ve Ark.}

Sakarya Üniversitesi' nde Laparoskopik Ürolojik Cerrahi: Başlangıç Deneyimlerimiz 